\title{
Reliability of Water Quality Test Strips for Field Measurement of Nutrients Essential for Developing Mosquito Larvae
}

\author{
Forest I. Isbell and David R. Mercer \\ Department of Biology \\ University of Northern lowa \\ Cedar Falls, lowa 50614-0421 USA \\ Mohammad Z. Iqbal \\ Department of Earth Science \\ University of Northern lowa \\ Cedar Falls, lowa 50614-0335 USA
}

Received: July 20, 2004 Accepted: October 19, 2004

\begin{abstract}
We tested the reliability of water quality test strips for field-analysis of nitrate and phosphate against laboratory-based standard methods for water samples drawn from a variety of natural and artificial sites used by mosquito larvae for development. Nitrate test strip measurements were compared with those from ion chromatographic analysis and an ion-selective electrode. Phosphate test strip measurements were compared to laboratory persulfate digestion followed by an ascorbic acid colorimetric assay. It was concluded that while the standard methods were the most reliable, nitrate-sensitive test strips were acceptable for measuring moderate nitrate concentrations, but phosphate-sensitive test strips were not reliable in measuring the forms of phosphorus available to mosquito larvae.
\end{abstract}

\section{INTRODUCTION}

Excess nutrients in lowa water bodies may negatively affect "desirable" aquatic populations while increasing production and growth of "pest" organisms. Because much of the land surrounding lakes and wetlands is used for farming, agricultural chemicals and sediments are frequent sources of nitrogen and phosphorus in water bodies. Nitrogen and phosphorus are essential for biomolecular structure and energy transfer and storage for all living things, and thus the availability of each in a local environment has a deterministic effect on the quantity and vigor of the organisms present. Therefore, methods for estimating nitrogen and phosphorus concentrations in the field can be used to investigate populations of aquatic organisms, including mosquitoes (Diptera: Culicidae). The reliability of these field methods may be determined by comparison with standard laboratory procedures [1].

Mosquitoes spend their larval and pupal stages in a wide variety of natural pools and artificial containers that hold water and accumulate nutrients. Mosquito larvae filter-feed on particulate organic matter and bacteria suspended in the water, and browse both on submerged surfaces and shallow sediments [2]. High resource availability during larval developmental stages may increase both numbers and sizes of resulting adults. Large female mosquitoes generally survive longer in nature, produce more eggs, are more successful at getting blood meals, and are often better vectors of disease to humans and their domestic animals. If excess nutrients enter lowa water bodies, mosquito numbers and disease transmission might be increased. 
Mosquito larval production was positively correlated with the nitrogen available from decaying leaf sources in treehole habitats [3]. Furthermore, growth efficiency of bacteria (a critical component of the larval diet) was shown to be dependent on the availability of phosphorus in lakes [4]. Studies on Anopheles gambiae Giles have shown that larvae feed on algae [5], and algal blooms frequently result from the eutrophication of aquatic habitats. Anopheles quadrimaculatus Say larval distribution and survivorship were shown to directly relate to food resource availability [6]. Likewise, nutrient-rich pools of water are preferred by Culex species, including major vectors of disease.

Nitrogen in the form of nitrate (i.e., $\mathrm{NO}_{3}{ }^{-} \mathrm{N}$ ) is naturally found in aquatic habitats as the result of decomposition of organic matter. Artificial sources of nitrate include automobile and industrial emissions, municipal and industrial wastewater, and agricultural runoff (i.e., fertilizers, pesticides). Concentrations of nitrate are usually between 0.1 and $4 \mathrm{mg} \mathrm{NO}_{3}^{-}-\mathrm{N} \mathrm{L}^{-1}$ in field samples collected from lakes or other natural water bodies, with most unpolluted samples less than $1 \mathrm{mg} / \mathrm{L} \mathrm{mg} \mathrm{NO}{ }_{3}^{-}-\mathrm{N} \mathrm{L}^{-1}$ [7]. However, sewage effluent and comparable wastewaters may have $\mathrm{NO}_{3}{ }^{-} \mathrm{N}$ concentrations in excess of $20 \mathrm{mg} \mathrm{NO}_{3}^{-}-\mathrm{N}$ $\mathrm{L}^{-1}$. The EPA has established $10 \mathrm{mg} \mathrm{NO}_{3}^{-}$ $\mathrm{N} \mathrm{L}^{-1}$ as the legal limit for drinking water [8]. Phosphorus, another essential nutrient, frequently limits the primary productivity of freshwater ecosystems. Unlike nitrogen, phosphorus has no atmospheric phase and naturally forms only when substrate or biomass is broken down. Because it is generally a limiting factor, excess phosphorus often contributes to eutrophication of lakes or ponds. Nearly all phosphorus in waters and wastewaters is in some form of phosphate [1]. Orthophosphate is the inorganic form that is dissolved in solution and is most available to organisms. Condensed phosphates are in particulate form in suspended colloids or precipitated sediments. Organically bound phosphates are present in the biomass of aquatic organisms. Orthophosphates may come from agricultural runoff, detergents, soaps, septic leachate, sewage effluent, or precipitation. Organic phosphates are the products of many biological processes.
Phosphates in bottom sediments are less available to aquatic organisms. However, these precipitated forms are generally in equilibrium with the orthophosphate present, so water may be saturated with soluble orthophosphate.

A variety of laboratory-based standard methods are available for estimating concentrations of dissolved nutrients. However, in order to apply these methods to field collected samples, samples often require manipulation in the field, storage on ice, and laboratory analysis within short time periods. We attempted to compare these methods with nutrientspecific test strips usable in the field.

Water quality test strips provide a convenient way to measure concentrations of several essential nutrients in the field for a variety of research purposes. They quickly provide results and do not require transport of water samples to a laboratory. A chemically sensitive pad on the strip is dipped into the water sample. A color change occurs within a prescribed period that indicates nutrient concentration when compared to a prepared titration series often printed on the label. Test strips are commercially available for several specific dissolved nutrients including dissolved nitrate, dissolved nitrite, and dissolved phosphate.

Laboratory based methods likewise rely upon comparison of unknown samples against known concentration standards. Total solubilized nitrate may be measured potentiometrically using a nitrate ionselective electrode (ISE). The electrode has a semipermeable membrane that allows a voltage to establish that is directly proportional to the nitrate ion concentration.

Ion chromatography is a useful method for determining ion concentrations in source water, drinking water, wastewater, industrial cooling water, acid rain, anionic counterions in pharmaceuticals and synthetic peptides, foods, and beverages. A typical anion column is capable of separating as many as seven different anions. Accuracy and precision are significantly superior to other electrode and colorimetric methods [1].

Phosphorus analyses should measure the desired form of the nutrient. Samples may or may not be filtered to measure orthophosphate or total 
phosphorus (dissolved plus condensed forms) respectively. To measure the total phosphorus available to aquatic organisms all forms not in solution are converted to orthophosphate by a digestion method, and total dissolved phosphate is subsequently measured with a colorimetric method [1].

\section{METHODS}

Water samples were collected from a field survey of potential mosquito developmental sites that included natural (e.g., wetlands, forest pools, ditch puddles) and artificial (e.g., industrial containers, farm containers and tires) habitats. The second of multiple dip samples was saved after invertebrates were counted and removed for other study. Unfiltered water samples were used for all field and laboratory procedures, and the same individual performed all tests to maintain consistency. Aquachek water quality chemical test strips (Hach Company, Loveland, CO) were used to test dissolved nitrate, dissolved nitrite, and orthophosphate in the field. The water from each site was transferred to a $120 \mathrm{~mL}$ sterile (new or acid washed) plastic bottle and stored on ice during transport to the laboratory. About 20 $\mathrm{mL}$ of each sample were transferred to a scintillation vial for nitrate analysis. Total phosphorus analysis was performed on the remaining volume. All samples were stored at $4^{\circ} \mathrm{C}$ prior to analysis $(<24 \mathrm{~h})$. Any water sample outside the detection limits of a standard method was diluted and reanalyzed.

Nitrate electrode tests followed the standard method [1] for ion-selective electrode analyses, using a Vernier ${ }^{\mathrm{TM}}$ Nitrate Ion-Selective Electrode (Vernier ${ }^{\mathrm{TM}}$ Software and Technology, Beaverton, OR) with resolution of $\pm 7 \%$ of the sample reading. This electrode has a range of measurement between 0.1 and 14,000 mg $\mathrm{NO}_{3}^{-}-\mathrm{N} \mathrm{L}^{-1}$. Measurements from the electrode were taken from a computer operating with version 2 of a Logger Pro software program (Vernier ${ }^{\mathrm{TM}}$ Software and Technology) that generates a standard curve, rather than requiring a dilution series. Sample concentrations were observed to be adequately stable for measurement without a buffer solution. Also, the probe was recalibrated each day using 10 and $100 \mathrm{mg}$ $\mathrm{NO}_{3}^{-}-\mathrm{N} \mathrm{L}^{-1}$ standard solutions.
Ion chromatography analyses followed the standard method (1) and used a Dionex@ DX-100 Ion Chromatograph with a suppressed conductivity setting, an IonPac ${ }^{\circledR}$ AS4A-SC column and a Dionex 4270 integrator (Dionex Corporation, Sunnyvale, CA). The instrument was calibrated using four standard solutions containing 5, 25, 30, and $65 \mathrm{mg} \mathrm{NO}_{3}^{-} \mathrm{L}^{-1}$. The chromatograph operated at a flow rate $=2.0 \mathrm{~mL} \mathrm{~min}^{-1}$ to obtain optimal peak detection. The integrator was programmed to express measurements in $\mathrm{mg} \mathrm{L}^{-1}$. The resolution of this instrument for nitrate was \pm $0.17 \%$ of the measured concentration (approximately $\pm 0.5 \mathrm{mg} \mathrm{NO}_{3}^{-}-\mathrm{N} \mathrm{L}^{-1}$ for the tested range). Samples were filtered as they were injected into the instrument using Sterile Acrodisc $\AA 0.45 \mu \mathrm{m}$ filters (Gelman Sciences, Ann Arbor, MI). A $1.8 \mathrm{mM} \mathrm{Na}_{2} \mathrm{CO}_{3}$ I $1.7 \mathrm{mM} \mathrm{NaHCO}_{3}$ eluent solution was used for isocratic elution of anions, and to frequently flush both the exchange column and the guard column for maximum precision. After every 10 - 15 samples, double-deionized water was injected to check the baseline.

Phosphorus laboratory tests were done to determine the total phosphorus present in the collected water samples. To oxidize the condensed organic sources of phosphate to orthophosphate, a persulfate digestion method [1] was followed. In this digestion, sulfuric acid and ammonium persulfate were mixed with $50 \mathrm{~mL}$ of the sample and autoclaved for 30 minutes. Total phosphate was then measured using an ascorbic acid colorimetric method [1] with a GENESYS ${ }^{\mathrm{TM}} 10 \quad$ Spectrophotometer (Thermospectronic, Rochester, NY) at 880 $\mathrm{nm}$. In this assay, the orthophosphate from the digestion reacted with ammonium molybdate, potassium antimonyl tartrate, and ascorbic acid to form molybdenum blue (a colored compound) detectable in the range of $0.15-1.3 \mathrm{mg} \mathrm{P} \mathrm{L}^{-1}$.

Correlation analyses were used to test for significant correlations between pairs of measurements. Only samples that were analyzed within $24 \mathrm{~h}$ of collection were considered. Paired $t$-tests were used to compare pairs of means for the field and laboratory assays for each nutrient. Because variances differed greatly for most pairs of means, paired $t$-tests were performed on 


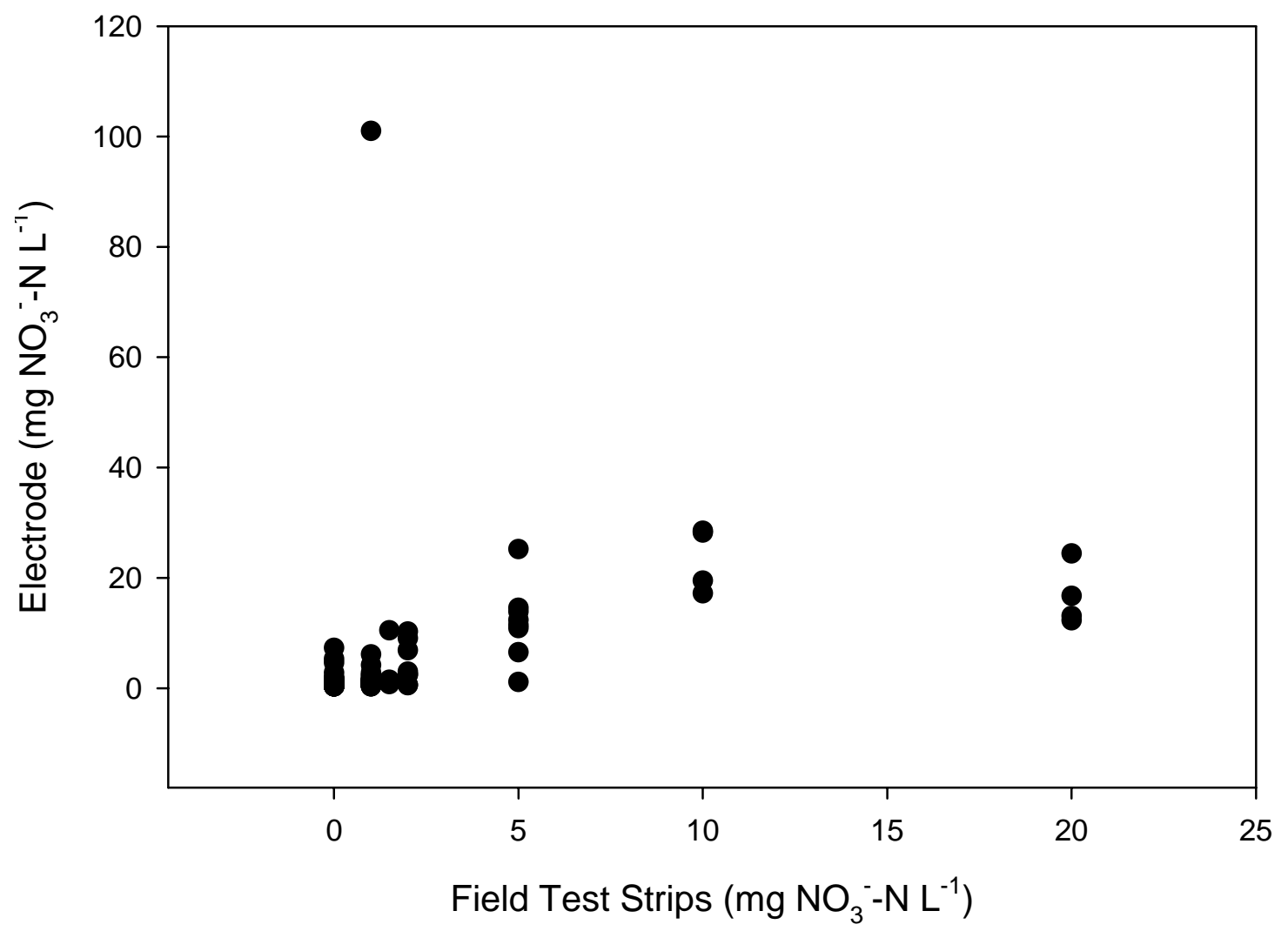

Figure 1. Ion chromatography versus chemical test strip estimates of dissolved nitrate in water samples.

$\log _{10}(x+1)$ transformed data. Statistica [9] was used for all data analyses.

\section{RESULTS}

Estimates of dissolved nitrate concentrations in the field using test strips were significantly correlated with both standard laboratory method estimates (Figure 1 \& Figure 2), although mean estimates for the nitrate tests differed significantly between field and laboratory methods (Table 1). Estimates of dissolved nitrate by the two laboratory methods were significantly correlated and produced equal means (Table 1). Mean values of dissolved nitrate were significantly lower for the field test strips than by either laboratory method (Table 1; $t$-test for paired samples performed on pairs of $\log _{10}[x+1]$ transformed data due to unequal variances). The test strip field estimates for dissolved nitrate were not significantly correlated with estimates for dissolved nitrite (Pearson's correlation coefficient $r=-0.088, \mathrm{p}=0.172, \mathrm{~N}=244$ ). Adding field test strip nitrate and nitrite results improved the correlations slightly with both the ion chromatography $(r=0.583)$ and electrode $(r=0.430)$ methods.

The correlation was not significant between estimates of phosphorus in the water using chemically selective test strips and the laboratory persulfate digestion method (Figure 3). For 41 samples, the means of field and laboratory estimates of phosphorus were significantly different; contrary to the nitrogen estimates, however, the field estimates were much greater than the laboratory estimates (Table 1).

\section{DISCUSSION}

We initially used chemical test strips for field estimates of nutrients following the recommendations of the lowa Department of Natural Resources for their Volunteer Water 


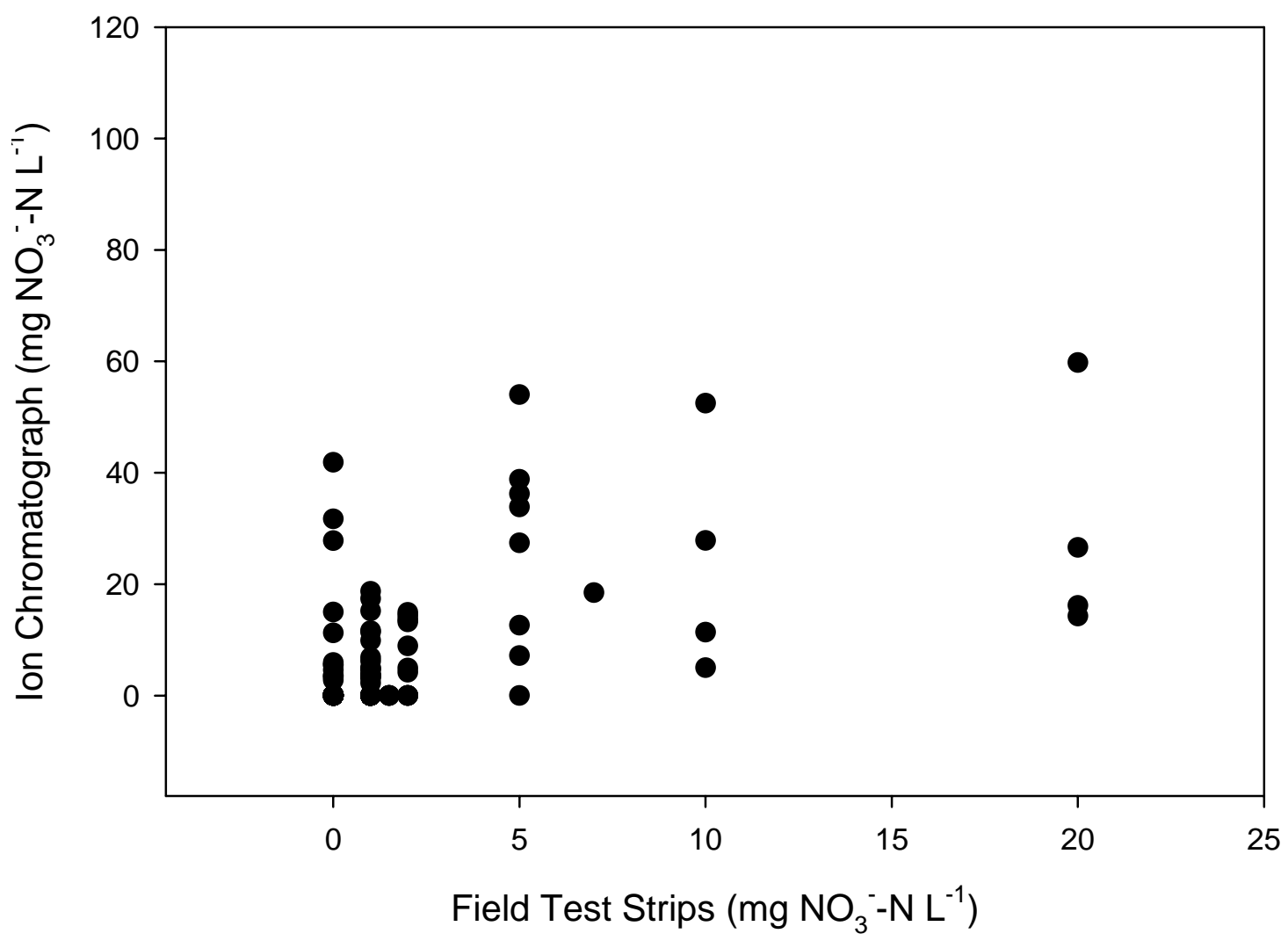

Figure 2. Ion-selective electrode versus chemical test strip estimates of dissolved nitrate in water samples.

Quality Monitoring Program. Although the standard laboratory methods are both accurate and precise, they require special handling of samples, collected samples may suffer "bottle effects", and analyses must be done soon after samples are collected. Nitrate test strips provided immediate results in the field and correlated significantly with both standard laboratory methods. However, the correlations were best for intermediate to high nitrate concentrations (i.e., 5 to $20 \mathrm{mg}$ $\mathrm{NO}_{3}^{-}-\mathrm{N} \mathrm{L}^{-1}$ ) but poor at low concentrations where one method indicated zero nitrate while the other method suggested measurable concentrations (Figures 1 \& 2). Thus, the test strips may be most appropriate for preliminary analyses of large numbers of field water samples with intermediate nitrate content. Because the legal allowable limit for dissolved nitrate in drinking water is relatively low (i.e., $10 \mathrm{mg}$ $\mathrm{NO}_{3}{ }^{-}-\mathrm{N} \mathrm{L}^{-1}$ ), the test strips may be inappropriate for their use in water quality monitoring.
Although there was higher agreement between test strip estimates and the ion chromatography method than with the nitrate-sensitive electrode, one outlier accounted for much of this difference (Figure 2). Ignoring this sample, with an electrode value $>100 \mathrm{mg} \mathrm{NO}_{3}^{-}-\mathrm{N} \mathrm{L}^{-1}$, improved the correlation between electrode and test strip nitrate estimates $(r=0.770, \mathrm{p}$ $<10^{-6}, N=178$ ) as well as the correlation between the two laboratory methods ( $r=$ $0.703, \mathrm{p}<10^{-6}, \mathrm{~N}=178$ ). The laboratory methods were more similar in mean nitrate content than either one was with the test strip estimates; therefore, the test strips appear to be less sensitive for nitrate than the laboratory methods. Both laboratory nitrate estimates were -3 -fold greater than the test strip estimates. Although the test strips might be insensitive to nitrates tied up in colloids, the test strips appear to be acceptable estimators of nitrate levels for field measurements. Estimates of total dissolved nitrogen might be further improved by adding the results of dissolved nitrite ion. 


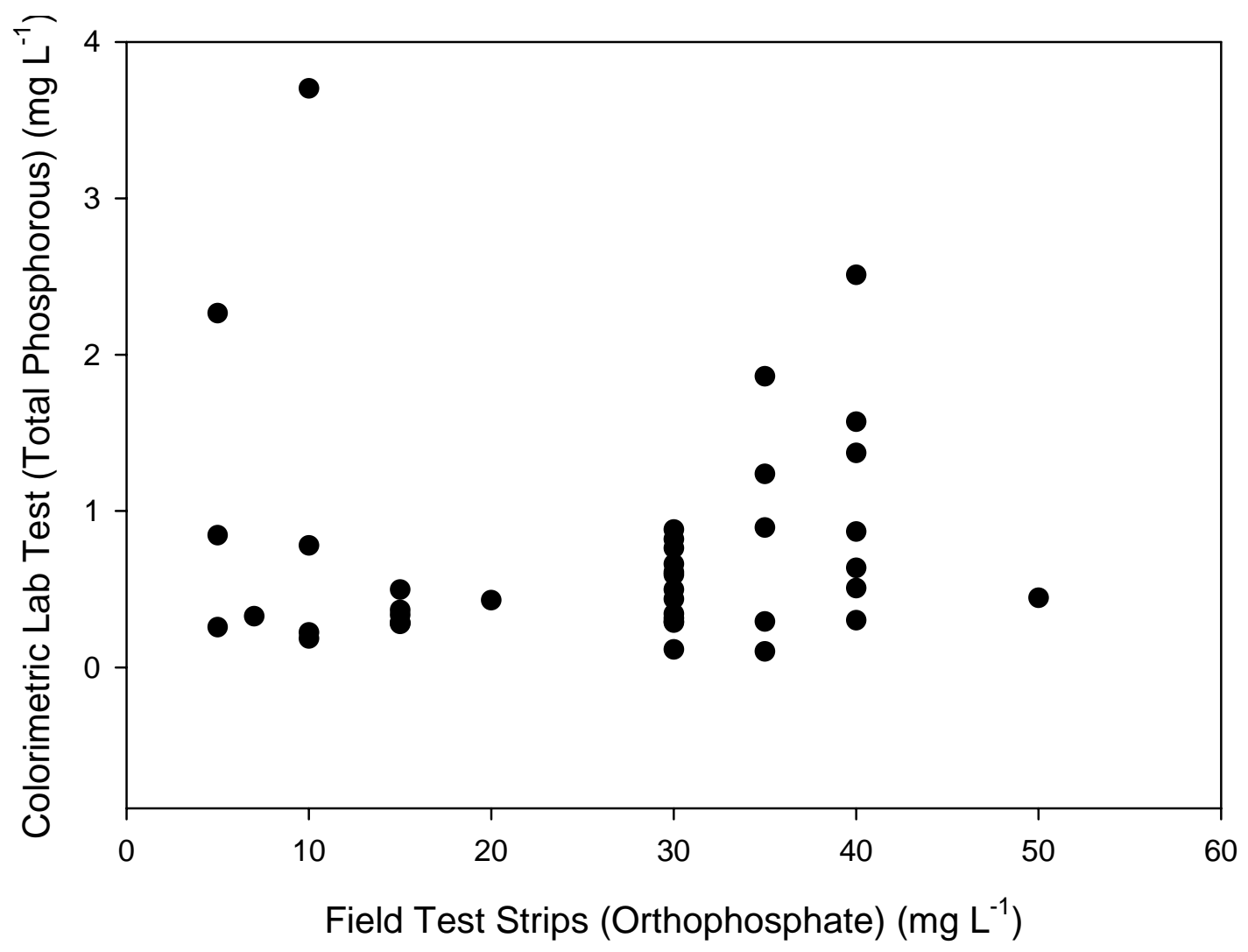

Figure 3. Laboratory colorimetric assay of total phosphorus versus chemical test strip estimates of orthophosphate in water samples.

By contrast, the phosphate chemical test strips appear to be unacceptable for estimating forms of phosphorus that might be consumed by mosquitoes. The phosphate test strips turned shades of gray in the field when exposed to higher concentrations of phosphate rather than the purple-gray indicated on the label. As a result, test strips were exposed to standard phosphate solutions in the laboratory, but showed color changes similar to those observed in the field. This suggests that interference in field samples was not the likely cause of the test strip malfunction. Even though the phosphate test strips theoretically measure only orthophosphate whereas the laboratory methods estimate total water phosphorus (orthophosphate plus condensed phosphate), our mean test strip estimates were $\sim 35$-fold greater than the mean laboratory estimates. Mosquito larvae filter feed and browse surfaces, thereby benefiting from both dissolved phosphate (either by direct consumption or when it supports bacterial growth) and condensed phosphate (when they take in suspended colloids). Therefore, a laboratory-based analysis is probably necessary for estimating this limiting nutrient.

Dodds [10] argued against using dissolved nitrogen and dissolved phosphate to represent nutrient contents in surface water. Although these are the forms most accessible to aquatic organisms, total nitrogen and total phosphorus are better measures of nutrient status. Because mosquito larvae are known to consume microorganisms [11], food bound tightly to mineral and algal surfaces $[11,12]$, leaf litter found in treehole ecosystems [13], in addition to dissolved nutrients [11], the ideal test method for determination of nutrient availability would consider each. These are all sources of the nutrients here discussed, and compose a diet adequate for development and proliferation. For the phosphorus analysis, the lab method might be used for each of these various forms 


\begin{tabular}{|c|c|c|c|c|c|c|c|c|}
\hline $\begin{array}{c}\text { Test } \\
\text { Method }\end{array}$ & $\begin{array}{c}\text { Pearson's } \\
r\end{array}$ & p & $\mathbf{N}$ & Mean & $\begin{array}{l}\text { Standard } \\
\text { deviation }\end{array}$ & DF & t-statistic & $\mathbf{P}$ \\
\hline $\begin{array}{l}\text { Test strip } \\
\text { for nitrate }\end{array}$ & 0.58 & $<10^{-6}$ & 194 & 1.38 & 3.22 & 193 & $-2.08^{\star}$ & 0.039 \\
\hline $\begin{array}{l}\text { Lab IC for } \\
\text { nitrate }\end{array}$ & & & & 4.19 & 10.1 & & & \\
\hline $\begin{array}{l}\text { Test strip } \\
\text { for nitrate }\end{array}$ & 0.43 & $<10^{-6}$ & 179 & 1.36 & 3.33 & 178 & $-8.71^{*}$ & $<10^{-6}$ \\
\hline $\begin{array}{l}\text { Lab } \\
\text { electrode } \\
\text { for nitrate }\end{array}$ & & & & 3.07 & 8.91 & & & \\
\hline $\begin{array}{l}\text { Lab } \\
\text { electrode } \\
\text { for nitrate }\end{array}$ & 0.39 & $<10^{-6}$ & 179 & 3.07 & 8.91 & 178 & -1.51 & 0.132 \\
\hline $\begin{array}{l}\text { Lab IC for } \\
\text { nitrate }\end{array}$ & & & & 4.29 & 10.4 & & & \\
\hline $\begin{array}{l}\text { Test strip } \\
\text { for } \\
\text { phosphate }\end{array}$ & 0.012 & 0.940 & 41 & 26.0 & 12.3 & 40 & $24.9 *$ & $<10^{-6}$ \\
\hline $\begin{array}{l}\text { Lab } \\
\text { analysis for } \\
\text { phosphate }\end{array}$ & & & & 0.738 & 0.729 & & & \\
\hline
\end{tabular}

Table 1. Correlations and comparisons of mean estimates for dissolved nitrate and phosphate determined by field and laboratory methods. Legend: All units in parts per million $\left(\mathrm{mg} \mathrm{L}^{-1}\right)$. Asterisk $\left(^{*}\right)$ indicates comparisons done on $\log _{10}(x+1)$ data.

potentially present in the samples by utilizing a digestion method capable of converting all condensed forms of phosphorus to orthophosphate. The field test strips measured only the dissolved forms of nutrients, and were shown to differ significantly from the standard laboratory colorimetric assay.

In conclusion, the laboratory methods are more accurate than the test strips for estimates of both nitrogen and phosphorus concentrations in mosquito developmental habitats. Nonetheless, the nitrate test strips are probably acceptable for most field studies, particularly when a large number of samples can be taken. The phosphorus test strips measure only orthophosphate, which is only part of the sum of phosphorus that mosquito larvae are likely to consume. Because phosphorus is frequently the most limiting nutrient in an ecosystem, it is critical to test all available sources. Since mosquito larvae also consume suspended colloidal forms of phosphorus, this may not be possible with the test strips.

\section{ACKNOWLEDGEMENTS}

This research was generously supported by the Roy J. Carver Charitable Trust, the lowa Space Grant Consortium and the lowa State 
Water Resources Research Institute. Additional support was provided by the College of Natural Sciences and the Graduate College of the University of Northern lowa. We thank the Black Hawk County Conservation Board for allowing access to Beaver Valley Wetlands. Student researchers included Forest I. Isbell, Keri A. Leymaster and Sara L. Sheeley. John Bumpus, Dwayne Bartak and Edward Brown provided technical advice and facilities for laboratory assays. William Stigliani and Maureen Clayton were UNI Project Coordinators for the Roy J. Carver Charitable Fund. The views and conclusions contained in this document are those of the authors and should not be interpreted as necessarily representing the official policies, either expressed or implied, of the U.S. Government.

\section{REFERENCES}

1. Clesceri, L. S., A. E. Greenberg, A. D. Eaton, Standard Methods for the Examination of Water and Wastewater: $20^{\text {th }}$ Ed. American Public Health Association, Washington, DC. (1998).

2. Merritt, R. W., R. H. Dadd, E. D. Walker. Feeding behavior, natural food, and nutritional relationships of larval mosquitoes. Annu. Rev. Entomol. vol. 37, 349-376 (1992).

3. Walker, E. D., Michael G. Kaufman, Matthew P. Ayres, Mark H. Riedel and R. W. Merritt. Effects of variation in quality of leaf detritus on growth of the eastern tree-hole mosquito, Aedes triseriatus (Diptera: Culicidae). Can. J. Zool. vol. 75, 706-718 (1997).

4. Smith, Erik M. and Yves T. Prairie. Bacterial metabolism and growth efficiency in lakes: The importance of phophorous availability. Limnol. Oceanogr. vol. 49(1), 137-147 (2004).

5. Gimnig, John E., Maurice Ombok, Samson Otieno, Michael G. Kaufman, John M. Vulule and Edward D. Walker Density-dependent development of Anopheles gambiae (Diptera: Culicidae) larvae in artificial habitats. J. Med. Entomol. vol. 39(1), 162-172 (2002).

6. Wallace, J. R. and R. W. Merritt. Influence of microclimate, food, and predation on Anopheles quadrimaculatus (Diptera: Culicidae) growth and development rates, survivorship, and adult size in a Michigan pond. Environ. Entomol. vol. 28(2), 233-239 (1999).

7. Johnson, R., S. Holman, D. Holmquist, Water Quality With Computers: First Ed. Vernier Software and Technology, Beaverton, OR (1999).

8. EPA Ground and Drinking Water Factsheet for Nitrate/Nitrite, http://www.epa.gov/safewater/ contaminants/dw_contamfs/nitrates.html (2004).

9. Statistica, Softstat, Tulsa, OK, USA (1995).

10. Dodds, W. K. The misuse of soluble reactive phosphorus and inorganic nitrogen to indicate nutrient status of surface waters. J. N. Am. Benthol. Soc. vol. 22, 171-181 (2003).

11. Wallace, J. B., R. W. Merritt. Filterfeeding ecology of aquatic insects. Annu. Rev. Entomol. vol. 25, 103-132 (1980).

12. Cummins, K. W., M. J. Klug. Feeding ecology of stream invertebrates. Annu. Rev. Ecol. Syst. vol. 10, 147-172 (1979).

13. Fish, D., S. R. Carpenter. Leaf Litter and Larval Mosquito Dynamics in tree-Hole Ecosystems. Ecology vol. 63, 283-288 (1982).

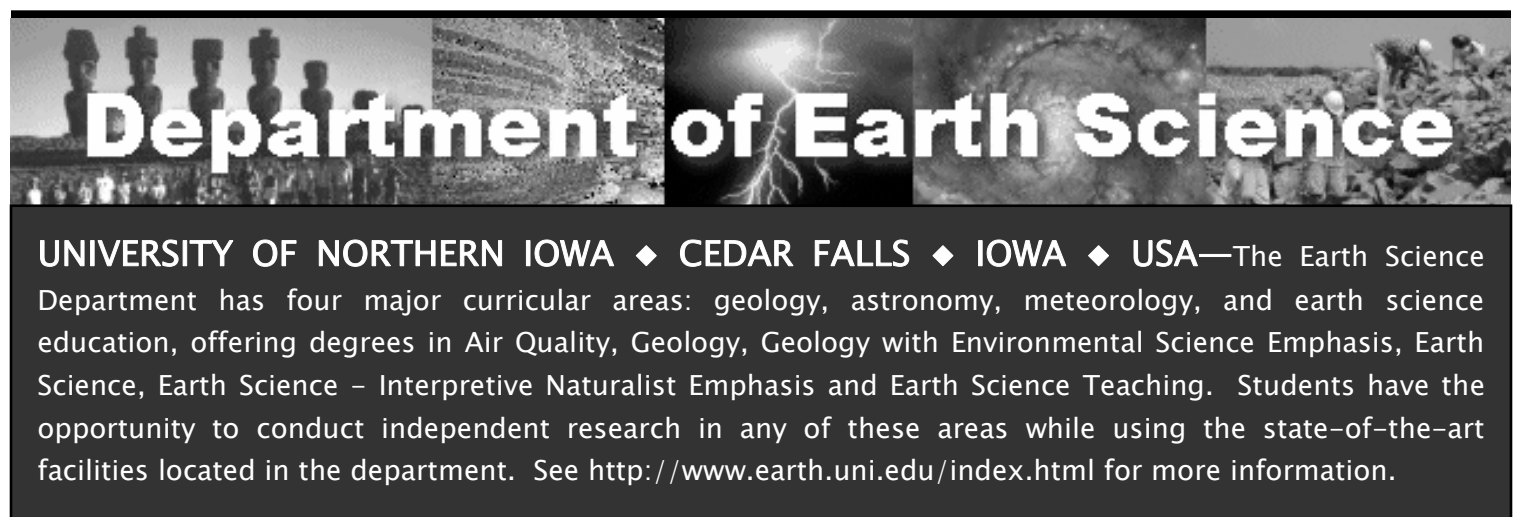

